Rosser-Limiñana $\mathcal{E}$ de Juana-Espinosa, 2019

Volume 5 Issue 2, pp. 700-711

Date of Publication: 26 ${ }^{\text {th }}$ September 2019

DOI- https://dx.doi.org/10.20319/pijss.2019.52.700711

This paper can be cited as: Rosser-Limiñana, A., E de Juana-Espinosa, S., (2019). European Good

Practices on Inclusion of Migrant and Roma Children in Schools. PEOPLE: International Journal of

Social Sciences, 5(2), 700-711

This work is licensed under the Creative Commons Attribution-Non Commercial 4.0 International License. To view a copy of this license, visit http://creativecommons.org/licenses/by-nc/4.0/ or send a letter to Creative Commons, PO Box 1866, Mountain View, CA 94042, USA.

\title{
EUROPEAN GOOD PRACTICES ON INCLUSION OF MIGRANT AND ROMA CHILDREN IN SCHOOLS
}

\author{
Ana Rosser-Limiñana \\ Department of Communication and Social Psychology, University of Alicante, Alicante, Spain \\ ana.rosser@ua.es \\ Susana A. de Juana-Espinosa \\ Department of Business Organization, University of Alicante, Alicante, Spain \\ susana.espinosa@ua.es
}

\begin{abstract}
Children of migrant and Roma origins often face situations of exclusion. As a result, their educational achievements are generally lower, while their chances of leaving compulsory education are greater. This situation entails greater risks of social marginalisation, integration failure and, ultimately, poverty, which in turn has adverse effects on the social development and economic growth of the host country in the long term. The RoMigSc Project has compiled a catalogue of good practices in order to show successful initiatives in the field of school inclusion of Roma and migrant children, so as to encourage mutual learning and knowledge transfer among the EU Member States of the most effective school inclusion policies relating to migrant and Roma children across Europe. To do so, an Implementation research study was conducted. It shed light, on the one hand, on a number of successful actions and programmes; and on the other, on certain difficulties and solutions that brought about improvements. Therefore, this
\end{abstract}


work contributes to the corpus of evidence on efficient strategies to encourage school inclusion and the lessons that can be learnt.

\section{Keywords}

Europe, Good Practices, Implementation Research, Inclusive School, Migrant Children, Roma Children

\section{Introduction}

Europe is a transnational society, and within it, migration is playing an ever-increasing role. A multiplicity of nationalities, regional identities and minorities are recognised as Roma people within the European Union (EU). The Roma minority has been transiting throughout Europe for a long time, sometimes voluntarily but often out of necessity, due to economic precariousness, discrimination and exclusion. More recently, changes in Europe following the south-eastern European civil wars or the destruction of Africa's traditional economy have in turn intensified migration and the number of refugees in Europe. Since many migrants are of school age, European schools are thus focusing their efforts on addressing the challenges and opportunities of migration and minorities.

Progress has certainly been made regarding the integration of minors in schools since the mid-twentieth century. However, the data also indicate that some groups, such as the Roma (European Union Agency for fundamental rights, 2014) and migrants (Hippe \& Jakubowski, 2018), present higher school failure and school-leaving rates, and few attend secondary school. Indeed, official governmental programs are often not enough to provide the professionals in school inclusion with the skills required and so closeted segregation happens (Czyż, 2018) To this end, the EU has placed education at the heart of the integration issue, calling on member states to reflect diversity in the school curriculum, to take into account young immigrants' specific challenges, to take preventive measures against poor school performance, to encourage

early schooling, and to increase their participation in higher education. In May 2009, the European Council established a new strategic framework for European cooperation in the field of education and training, within the new Education and Training Strategy, 2010 (European Union Council, 2010). Its Strategic Objective No. 2, "Facilitating the access of all to education and training systems", includes the promotion of measures to increase social cohesion among which the integration of migrants. 
Efforts in this line of work continued until the 2015 Paris Declaration (European Commission, 2015) was signed, in which the European Commission clearly centres its basic education policy guidelines around two key terms: "inclusion in diversity" and "equity". The EU published, as a result of this agreement, a document explaining its stance on Inclusion in diversity (European Union Council, 2017)

Support programmes have also been set up for minors in situations of greater social vulnerability. They are managed by public entities and/or NGOs with diverse goals: to raise families' awareness, to fight school absenteeism, to reinforce and support education, to improve language skills, etc.; that is, these programs aim to develop innovative and effective concepts to improve the situation of migrant and minority students in schools. Even though situations differ across member states, countries often share the same pedagogical challenges.

Which are the main fields of action? Have such efforts complied with the European Union's mandate and prior experience? Have they added any transnational value? These are some of the questions addressed by the project RoMigSc, Inclusion of Roma and Migrants in Schools: Trainings, Discussions and Youth Volunteer Activities (No. 580228-EPP-1-2016-1-SIEPPKA3-IPI-SOC-IN). Six different European countries participated and aimed to answer those questions; developing their interventions around a solid understanding of the situation while taking into account the challenges and innovative initiatives of the partner countries (RoMigSc).

The objective of the project is to contribute to a standard school model that is migrationfriendly and minority-friendly, particularly in the field of teacher and volunteer training. One activity was that of compiling each country's good practices concerning the integration of migrants and Roma in schools since, according to the Rogers' Change Theory model (Rogers, 2014), exchanges of experiences and GPs, combined with a deep analysis of the challenges and attempts to create solutions, contribute to finding solutions to create better opportunities for all regarding migration and a transnational society.

Good practices (GPs) can be understood as a coherent set of actions that have rendered good, or even excellent, service in a given context and which are expected to yield similar results in equivalent contexts. The best educational practices are defined as the wide range of individual actions, policies and programmatic approaches to achieve positive changes in students' attitudes or academic behaviours (Arendale, 2017). The description of the practices should contain the following information: (a) a detailed description; (b) critical implementation elements; (c) 
essential resources, both personal and financial; and (d) the process used to collect impact data in order to evaluate the practice rigorously.

In this work, an Implementation research (IR) study was carried out to discover which interventions, comparatively, proved to be most effective and to find solutions that improved results of inclusion of migrant and Roma children in schools. This way, knowledge is generated through group work efforts, and based on information combined with experience, context, interpretation and reflection (Davenport, De Long, \& Beers, 1998).

Therefore, the IR analyses not only the content of the collected practices but also the instrument itself, allowing the researcher to approach knowledge that is important to the organisation; it also facilitates understanding how this knowledge is transferred as well as the factors that drive or prevent such a transfer (O'Dell, 2001). The idea is to enhance mutual learning and the transfer of the most effective policies regarding these children's school inclusion among the EU Member States.

\section{Method}

An IR design is a research approach that transcends traditional research/practice barriers to facilitate the design of effective, sustainable and scalable educational interventions (Fishman, Penuel, Allen, Cheng, \& Sabelli, 2013). To this end, IR focuses on identifying and addressing multi-level factors that help or impede adopting or maintaining programme-based evidence, by identifying and applying specific implementation strategies (Forman, et al., 2013; Owens, et al., 2014).

Work teams from 6 European countries, all partners of the RoMigSc project (Slovenia, Germany, Italy, Macedonia, Turkey and Spain), participated in compiling and analysing GPs. A total of 44 GPs were compiled regarding Migrant $(n=25)$ and Roma children $(n=19)$. The distribution per country is related to the most frequent type of social reality in each country. 
Table 1: Number of GPs analysed per country and field of action

\begin{tabular}{|l|l|l|l|}
\hline & Migrant & Roma & Country total \\
\hline Slovenia & 4 & 5 & 9 \\
\hline Macedonia & 3 & & 3 \\
\hline Italy & 6 & 2 & 8 \\
\hline Turkey & 3 & 1 & 4 \\
\hline Germany & 6 & 6 & 12 \\
\hline Spain & 3 & 5 & 8 \\
\hline Total scope & 25 & 19 & 44 \\
\hline
\end{tabular}

Source: own

The GPs were selected after consulting experts from the different countries. Following Arendale's work (2017), each practice was chosen on the basis that it was considered promising, validated or exemplary, depending on the level of evidence that supported it. They were analysed based on the adaptation of the template offered by the European Commission's DirectorateGeneral for Employment, Social Affairs and Inclusion (Užpelkienė \& Brožaitis, 2014), and the compiled GPs from the 6 countries participating in the project. Figure 1 shows the steps followed to develop the evaluation tool.

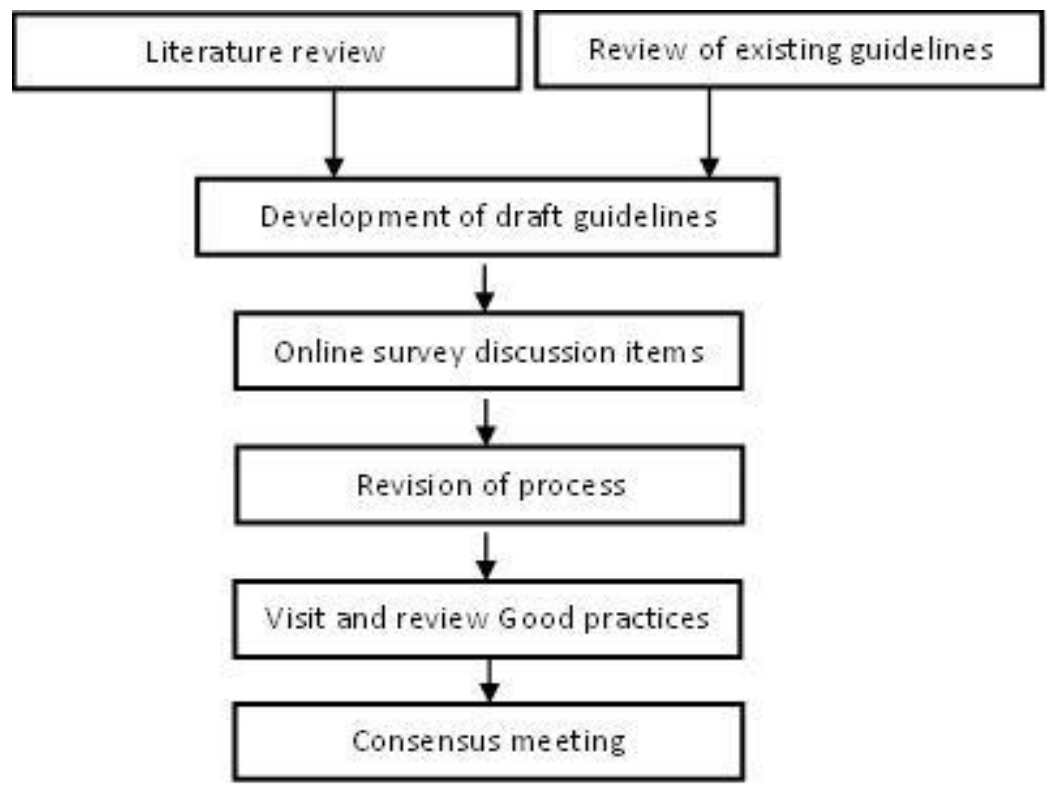

Figure 1: Development of the Evaluation Tool

Source: Own 
A common template was designed by the team members, including the final items providing information on GPs about inclusion/promotion of migrant and Roma diversity in schools. The variables in Table 2 were agreed upon to be part of the analysis template.

Table 2: Variables Analysed

\begin{tabular}{|c|c|}
\hline - $\quad$ Title of the policy or measure (English) & - $\quad$ Aims and objectives \\
\hline - $\quad$ Country & - $\quad$ Main activities/actions \\
\hline - $\quad$ Name of the responsible body or organization & - $\quad$ Geographical scope of practice \\
\hline - Geographical scope of the responsible body & - $\quad$ Target groups \\
\hline - $\quad$ Name and roles of other organizations involved & 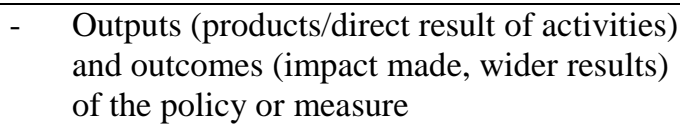 \\
\hline - $\quad$ Start/end year of implementation & - $\quad$ Key challenges faced/addressed \\
\hline - $\quad$ EU policy relevance & - $\quad$ Key conditions for success \\
\hline - $\quad$ National integration policy relevance & - $\quad$ Source of funding/Resources used \\
\hline $\begin{array}{l}\text { - } \quad \text { Specific policy, integration of Migrant/Roma } \\
\text { area/problem area being addressed }\end{array}$ & $\begin{array}{l}\text { - Method/type and results of assessment (if } \\
\text { any) }\end{array}$ \\
\hline & - $\quad$ Contact details \\
\hline
\end{tabular}

\section{Source: own}

To put the GPs at the disposal of an international audience, all the partners compiled a set of descriptions of said GPs regarding the integration of migrants and Roma in schools of their respective countries. This catalogue of GPs is available as part of the "useful resources" uploaded on the projects' website (www.romigsc.eu), under each country's report.

For the data analysis, after the data collection process, a categorical content analysis was carried out. The categorical content analysis (Andreu, 2002; Vázquez Sito, 1994) consists in breaking down textual data into thematic units to then group said units into categories by connections or similarities according to pre-established criteria. Recounting the number of times each category has been shown gives an overview of which topics are considered more or less relevant by the partners.

The unit of analysis was the paragraph and the decision to include each category was made from the coding of two judges. Its development was carried out in 5 phases: 1) initial reviewing of the different programmes; 2) open coding of the transcribed texts, according to previously defined questions; 3) coding by categories; 4) analysis of categorical thematic content 
following the recommendations of Vázquez Sito (1994); and 5) validation of the analysis by comparing the coding of the two judges. This way, the different components from each GP were analysed, such as: field of action, target groups, main activities carried out, and relevance at a European policy level.

Afterwards, the compliance of each GP and its impact with EU recommendations was evaluated. The study was completed with visits to several selected programmes to combine the explicit template information with that of personal experience.

\section{Results}

Table 3 shows the main areas of activity and the actions carried out, as well as the extent to which the BP addressed the recommendations of the European Union (EU Conclusions 2017/C 62 02). The programmes were essentially focused on people belonging to migrant and/or Roma groups, in particular to minors $(n=31)$, though also to the families of these minors $(n=$ 18) or adults of the group whether they were in charge of minors or not $(n=11)$. Another important block of actions was directed towards professionals: teachers, assistants, volunteers, etc. $(n=26)$ (Table 2$)$. The actions concentrated especially on school support $(n=16)$ and improving language skills $(\mathrm{n}=15)$, although many also focused on supporting families $(\mathrm{n}=14)$, promoting multiculturalism $(n=14)$, and the training of professionals working in multicultural environments $(\mathrm{n}=13)$ (Table 3).

Most GPs corresponded to the C10 recommendation $(n=37)$ of the European Union (2017/C62/02) highlighting the necessary cooperation between educational institutions, administrations and the different levels of civil society to increase inclusion and strengthen a sense of belonging and positive identity. They also followed C11 $(\mathrm{n}=32)$, advocating mutual support between educational institutions and other areas such as culture, employment, social services, etc. to guarantee inclusion in diversity. C1 $(\mathrm{n}=22)$ was also highly considered, which encourages the whole school community, stakeholders, and society in general, to jointly participate in issues beyond school life.

Other recommendations were also taken into account in a relevant way, albeit in fewer numbers: C15 $(\mathrm{n}=19)$, referring to the need to undertake the integration of third-party nationals, including language learning; C2 $(n=18)$ describing the need to promote democratic and 
inclusive schools that value diversity; and C9 $(\mathrm{n}=17)$ that considers it a priority to support teachers, educators and other professionals, attending to their motivation and competences.

Table 3: Fields of Action and Actions Taken

\begin{tabular}{|c|c|c|}
\hline \multicolumn{2}{|c|}{ Fields of action } & $\mathrm{n}$ \\
\hline \multirow[t]{8}{*}{ Target groups } & Immigrant or Roma minors & 31 \\
\hline & Parents & 18 \\
\hline & Adults immigrants, refugees or Roma & 11 \\
\hline & Schoolteachers & 11 \\
\hline & University students & 4 \\
\hline & Pedagogical workers, assistants & 9 \\
\hline & Volunteers & 2 \\
\hline & Institutions & 7 \\
\hline \multirow[t]{12}{*}{ Actions } & School support & 16 \\
\hline & Language competences & 15 \\
\hline & Early school incorporation & 1 \\
\hline & Prevention of absenteeism & 6 \\
\hline & Extracurricular activities & 8 \\
\hline & Family support & 14 \\
\hline & Social inclusion & 10 \\
\hline & Leisure and cultural activities & 14 \\
\hline & Training of professionals & 13 \\
\hline & Training of adults & 3 \\
\hline & Job inclusion & 5 \\
\hline & Network & 7 \\
\hline \multicolumn{2}{|c|}{ EU Policies (2017/C 62/02) } & Recommendations \\
\hline \multirow[t]{4}{*}{ Extent of consideration } & Highly considered $(22 \mathrm{o}+\mathrm{GP})$ & $\mathrm{C} 10, \mathrm{C} 11, \mathrm{C} 1$ \\
\hline & Moderately considered (17 a 19 GP) & $\mathrm{C} 15, \mathrm{C} 2, \mathrm{C} 9$ \\
\hline & Poorly considered (11 a 14 GP) & C3, C4, C6, C8, y C13 \\
\hline & No consideration or hardly any & C5, C7, C12 у C14 \\
\hline
\end{tabular}

Source: Own

The study also made it possible to detect common difficulties and key challenges regarding the examined GPs, including a lack of guarantee of continuity when the programmes were not supported by the state and were subsidy-dependent. Another common challenge was to ensure the systematic evaluation of the impact of the programmes. Finally, funding restrictions often prevented this essential work to take place. 


\section{Discussion and Conclusions}

Children of migrant and Roma origins often face exclusion. As a result, their educational achievements are generally lower, while their chances of leaving compulsory education are greater. This situation entails a greater risk of social marginalisation, integration failure and, ultimately poverty, which in turn has adverse effects on the social development and economic growth of the host country in the long term.

One of the activities conducted within the European Project RoMigSc was to compile and analyse a catalogue of GPs to encourage mutual learning and the transfer of knowledge between different European Union members, with the aim of identifying policies and measures to improve approaches to include migrant and Roma children in schools.

The collaboration between the different countries made it possible to build a global vision of the intervention strategies carried out across the range of member states, the main elements to be taken into account, and a detecting the gaps that prevented maximum effectiveness (see Figure 1). Among the lessons learned from the use of GPs as a knowledge transfer method, it is worth noting the need to establish a quantitative/qualitative method in order to measure the success of the practice (measurement indicator), and to define areas of improvement. It was also necessary to use a shared template to determine the common aspects of the GPs and to make tacit knowledge tangible. Finally, the visits aimed at witnessing first-hand how certain programmes were implemented in different countries allowed to combine the template's explicit information with the tacit knowledge of personal experience, thus allowing to close the knowledge management cycle (Nonaka, 2007). This synthesis and transfer of best practices that were validated by international experiences undeniably adds value at a transnational level.

An overview of the GPs showed how school support played a major role in helping these children overcome existing barriers, and to avoid early school-leaving. It illustrated how important it was to learn the host country's language - in the case of both minors and adults - to facilitate integration, and that different stakeholders and collectives, beyond schools, intervene to favour multiculturalism and social inclusion. In addition, the training of the professionals is key, as it has been evidenced by other experiences in school inclusion (Baguisa \& Ang-Manaig, 2019).

The study's limitations notably include the GPs' convenience sampling, though we followed the experts' criterion for this purpose. Nevertheless, many GPs are still unfolding and 
do not have proven evidence yet. However, as pointed out by García-Ramírez, Albar, Morano \& Castro (2017), studying these types of practices allows drawing lessons from the realisation of programmes that can later be used as standards, thus defining the best programmes generated within a field of action. Furthermore, while different countries' respective cultural and political contexts are indeed different, as noted in the introduction, they often share the same pedagogical challenges. In order to overcome these limitations, future research avenues will entail looking for similar GP in other countries outside the scope of the original project as well as following the development of the ones currently under study during the next years to analyse their effect on the target population.

\section{Acknowledgements}

The work was carried out within the framework of the European project "RoMigSc, Inclusion of Roma and Migrants in Schools: Trainings, Discussions and Youth Volunteer Activities (PROJECT NUMBER - 580228-EPP-1-2016-1-SI-EPPKA3-IPI-SOC-IN), by the Erasmus+ Programme of the European Union.

\section{References}

Andreu, J. (2002). Las técnicas de análisis de contenido: una revisión actualizada. Fundación Centro Estudios Andaluces, 10(2), 1-34.

Arendale, D. R. (2017). EOA national best practices directory 2017 (3rd ed.). Minneapolis, MN: Educational Opportunity Association and University of Minnesota, College of Education and Human Development, Department of Curriculum and Instruction.

Baguisa, L. R., \& Ang-Manaig, K. (2019). Knowledge, skills and attitudes of teachers on inclusive education and academic performance of children with special needs. PEOPLE: International Journal of Social Sciences, 4(3), 1409-1425. https://doi.org/10.20319/pijss.2019.43.14091425

Czyż, A. K. (2018). Attitudes of polish schools' teachers towards the idea of inclusive education for disabled people. PEOPLE: International Journal of Social Sciences, 4(1), 542-554. https://doi.org/10.20319/pijss.2018.41.542554

Davenport, T., De Long, D., \& Beers, M. (1998). Proyectos exitosos de gestión del conocimiento. Harvard Deusto Business Review(85), 4-19. 
European Commission. (2015). Promoting citizenship and the common values of freedom, tolerance and non-discrimination through education. Retrieved from https://publications.europa.eu/en/publication-detail/-/publication/ebbab0bb-ef2f-11e58529-01aa75ed71a1

European Union Council. (2010, May 26). 2010/C 135/02 Council conclusions of 11 May 2010 on the social dimension of education and training. Retrieved from https://eurlex.europa.eu/legal-content/EN/TXT/HTML/?uri=OJ:C:2010:135:FULL\&from=EN

European Union Council. (2017). Conclusions of the Council and of the Representatives of the Governments of the Member States, meeting within the Council, on Inclusion in Diversity to achieve a High Quality Education For All. Retrieved from 2017/C 62/02: https://eurlex.europa.eu/legal-content/EN/TXT/HTML/?uri=CELEX:52017XG0225(02)\&from=EN

European Union Agency for Fundamental Rights (2016). Education: the situation of Roma in 11 EU Member States. Luxembourg: Publications Office of the European Union. doi:10.2811/815973

Fishman, B. J., Penuel, W. R., Allen, A.-R., Cheng, B. H., \& Sabelli, N. (2013). Design-Based Implementation Research: An Emerging Model for Transforming the Relationship of Research and Practice. In B. J. Fishman, \& W. R. Penuel, National Society for the Study of Education (Vol. 112, pp. 136-156). Chicago.

Forman, S. G., Shapiro, E. S., Codding, R. S., Gonzales, J. E., Reddy, L. A., Rosenfield, S. A., . . . Stoiber, K. C. (2013). Implementation science and school psychology. School Psychology Quarterly, 28(2), 77-100. https://doi.org/10.1037/spq0000019

García-Ramírez, M. A. (2017). Metodología de la intervención social. Implicaciones para la investigación práctica de la psicología comunitaria. . In I. Maya, M. García, \& F. Santolaya, Estrategias de intervención psicosocial (pp. 61-62). Madrid: Pirámide.

Hippe, R. \& Jakubowski, M. (2018). Immigrant background and expected early school leaving in Europe: evidence from PISA. Luxembourg: Publications Office of the European Union. doi:10.2760/111445

Nonaka, I. (2007). The knowledge creating company. Harvard Business Review, July-August, 96-104.

O'Dell, C. (2001). El Valor De La Gestión Del Conocimiento. Harvard Deusto Márketing y Ventas(46), 18-20. 
Owens, J. S., Lyon, A. R., Brandt, N. E., Warner, C. M., Nadeem, E., Spiel, C., \& Wagner, M. (2014). Implementation science in school mental health: Key constructs in a developing research agenda. School Mental Health, 6(2), 99-111. https://doi.org/10.1007/s12310013-9115-3

Rogers, P. (2014). La teoría del cambio, Síntesis metodológicas: evaluación de impacto $n^{\circ}{ }^{\circ}$. Florencia: Centro de Investigaciones de UNICEF.

RoMigSc. (n.d.). Project Goals. Retrieved from https://romigsc.eu/about/

Užpelkienè, L., \& Brožaitis, H. (2014). Monitoring good practices in the areas of Employment, Social Affairs and Inclusion. Luxembourg: European Commission.

Vázquez Sito, F. (1994). Análisis de contenido categorial: el análisis temático. . Barcelona: Unitat de Psicologia Social -Universitat Autònoma de Barcelona. 